\title{
Experimental Study of Dynamic Characteristics on Composite Foundation with CFG Long Pile and Rammed Cement-Soil Short Pile
}

\author{
Jihui Ding1, Yanliang Cao1, Weiyu Wang², Tuo Zhao², Junhui Feng ${ }^{3}$ \\ ${ }^{1}$ College of Civil Engineering, Hebei University, Baoding, China \\ ${ }^{2}$ Hebei Academy of Building Research, Shijiazhuang, China \\ ${ }^{3}$ China Metallurgical Design and Research Institute Co., Ltd., Baoding, China \\ Email: dingjihui@126.com
}

Received 28 November 2013; revised 28 December 2013; accepted 4 January 2014

Copyright @ 2014 by authors and Scientific Research Publishing Inc.

This work is licensed under the Creative Commons Attribution International License (CC BY). http://creativecommons.org/licenses/by/4.0/

(c) (7) Open Access

\section{Abstract}

Based on the idea of optimization design of pile type, the two kinds of the typical pile type are selected, which containing flexibility pile (e.g. rammed cement-soil pile is for short RCSP), and rigid pile (e.g. cement-flyash-gravel pile is for short CFGP). The three kinds of the composite foundation are designed, which are CFGP, CFG long pile and CFG short pile (for short CFGLP-CFGSP), CFG longshort pile and rammed cement-soil short pile (for short CFGLP-RCSSP). Natural earthquake is simulated by using the engineering blasting; the dynamic characteristics and dynamic response of the composite foundation are studied through field test. CFGLP-RCSSP is closed to linear relation. The bearing capacity of the four composite foundation of the CFGP, CFGLP-CFGSP, and CFGLPRCSSP in the site are $225 \mathrm{kPa}, 179 \mathrm{kPa}$, and $197 \mathrm{kPa}$, separately increases $150 \%, 98.8 \%$ and $119 \%$ compared to the natural foundation. The vibration main frequency is mainly depended on properties of foundation soil and piles between vibration source and measuring point, pilling load value. Horizontal vibration main frequency greater than the vertical vibration main frequency and the vertical vibration main frequency close to the first-order natural frequency of composite foundation. With the pilling load increasing, the CFGLP-RCSSP pile composite foundation combined frequency decreased. Under the same blast energy, the acceleration peak on the CFG pile composite foundation is less than CFGLP-CFGSP the corresponding values, as the load increases, the peak acceleration gently. CFG pile composite foundation is favorable on seismic. The distribution of peak acceleration is consistent within $4 \mathrm{~m}$ from pile top in the CFGLP_RCSSP composite foundation. The maximum of the horizontal acceleration peak along the pile body occurs at a distance of pile top 4 $m$ or the pile top, and that of vertical acceleration peak occurred at a pile top. 


\section{Keywords}

\section{Blasting Vibration; CFG Pile; Rammed Cement-Soil Pile; Combined Pile Composite Foundation; Dynamic Characteristics}

\section{Introduction}

The composite foundation is that the part soil body in the natural ground foundation is reinforced or replaced during the ground treatment, and load is born by reinforced body and soil body around the pile [1]. Design theory of single pile composite foundation is relatively mature, and has certain limitations and shortcomings. The pile stiffness is smaller and the pile body has certain bond strength in the flexible pile composite foundation. The most commonly flexible piles are mixing cement soil pile [2] [3], rammed cement-soil pile [4] [5] pile, and so on. The strength of the flexible piles is low and load can not be effectively transmitted to the lower part of the pile. When the top of the soil-cement pile is crushed, the side friction of the pile length range did not develop out.

The pile in the rigid pile (i.e. CFG pile) composite foundation has higher strength, with large adjustment range of bearing capacity of composite foundation [6]. Usually the rigid pile has happened with piercing failure, and the pile body material strength has not fully developed out. To give full play to the advantages of various types of pile, the composite foundation to form by different typed piles combined together [7] [8], can maximize the advantages of various types of pile. With the rapid development of economy, strength, length of pile in composite foundation can be greatly improved, and greatly improve the bearing capacity of composite foundation. The original design theory of composite foundation can not meet the requirements, and dynamic problems of composite foundation have become the focus of attention. Study on the seismic performance of the composite foundation is the main application of numerical analysis and simulation of the composite foundation of finite element software [9]-[11], this method still remain at the theoretical level, have not been applied to the actual design. Wang Weiyu, Zhao Tuo, Ding Jihui etc. studied dynamic characteristic and its influence factors of cement soil pile and CFG pile composite foundation under the action of the blasting vibration [12]-[15].

Optimization is made to CFG pile and rammed cement-soil pile, and the composite foundations of CFG pile, CFG long pile and CFG short pile, CFG long pile and rammed cement-soil pile are, the designed. The stress and dynamic characteristics of the three composite foundation are studied through field tests.

\section{The Introduction of the Test Site}

The test site is located in Shijiazhuang Heibei province. In the $20 \mathrm{~m}$ depth, the soil layers mainly are yellow silt clay, fine sand, middle sand and silt clay. In the $20 \mathrm{~m}$ driving depth, the underwater is not seen. There is not the harmful geologic action in the site. The main parameters of soil layer as shown in Table 1.

\section{Model Test and Scheme of the Site}

Three kinds of composite foundation model are designed: CFGP, CFGLP-CFGSP, CFGCP-RCSLP composite foundation. The model design parameter of composite foundation is shown in Table 2. CFG pile adopts C20 commercial concrete. Blasting is used as the vibration resource. The diameter of blasting hole is $50 \mathrm{~mm}$. The Explosives are buried in the hole and than backfill tamping. The vibration is picked by acceleration sensors. The arrangement of the piles and measuring elements are shown in Figures 1-4.

The upper load is supplied by pilling concrete block, and each load of the composite foundation is added by an electric pressure pump-hydraulic jack. The square steel is $2.0 \times 2.0 \mathrm{~m}$ as the loading plate.

\section{The Analysis of Experiments Result}

\subsection{Load-Settlement Curves}

Combining the three kinds load test of composite foundation, the load-settlement curves as shown in Figure 4. From Figure 4, compared with natural foundation, the bearing capacity of composite foundation of CFGP, CFGLP-CFGSP and CFGLP-RCSSP increases obviously and the deformation of composite foundation de- 
Table 1. Mainly parameter of soil layer.

\begin{tabular}{cccccc}
\hline No. & $h_{i} / m$ & $f_{a k} / \mathrm{kpa}$ & $E_{s} / \mathrm{Mpa}$ & $f_{s k} / \mathrm{kpa}$ & $f_{q k} / \mathrm{kpa}$ \\
\hline 1$)$ & 0.5 & 130 & 6.17 & 60 & 800 \\
$2)$ & 1.5 & 140 & 10 & 55 & 82 \\
$3)$ & 4.0 & 200 & 11.5 & 65 & 1500 \\
$4)$ & & 270 & 5.84 & 5000 \\
\hline
\end{tabular}

Where, $h_{i}$ is thickness of the soil layer; $f_{a k}$ is characteristic value of bearing capacity; $E_{S}$ is compression Modulus; $f_{s k}$ is ultimate shaft resistance; $f_{q k}$ is ultimate tip resistance.

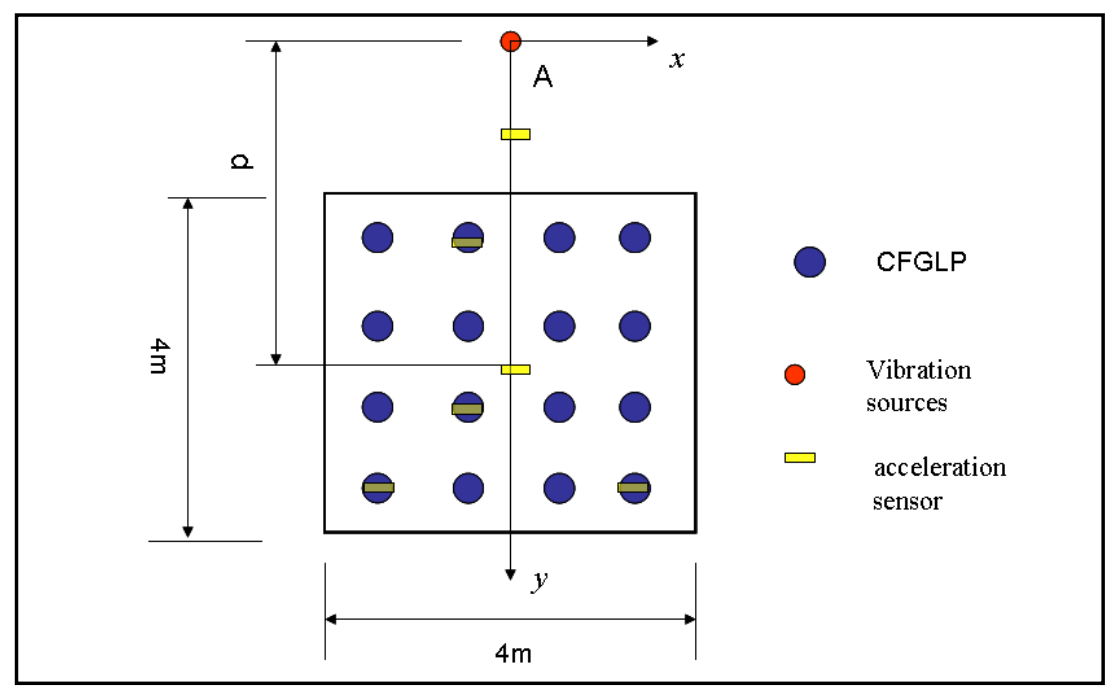

Figure 1. The arrangement of the piles and measuring elements of the Model 1.

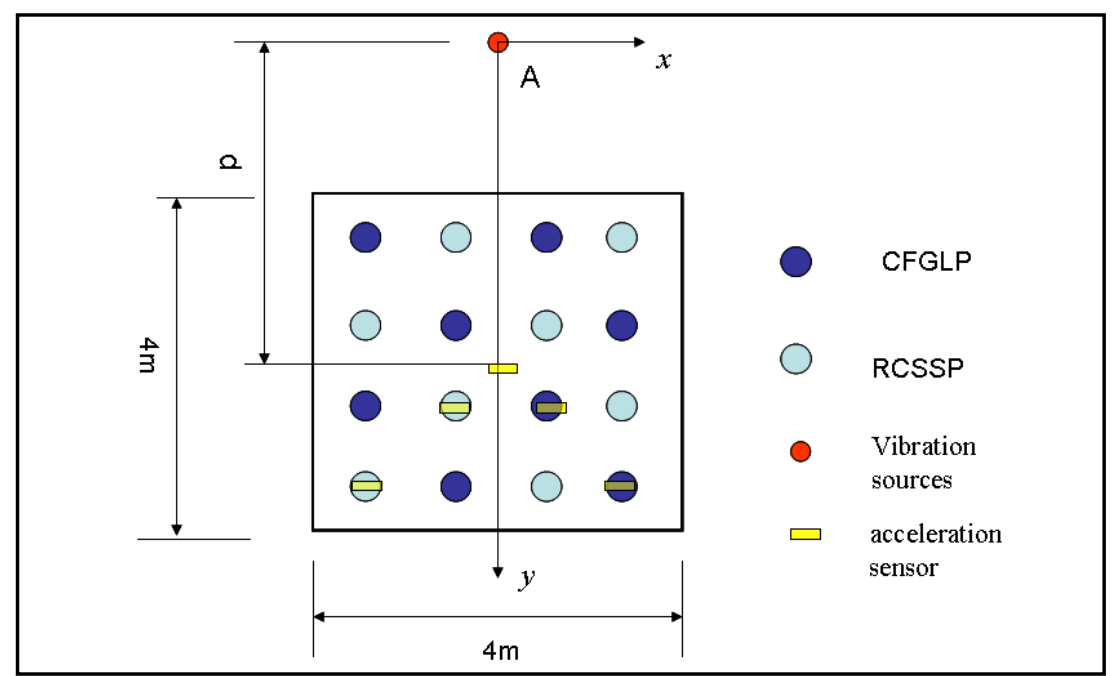

Figure 2. The arrangement of the piles and measuring elements of the Model 2.

creased compared to the Natural Foundation. The nonlinear degree of the $p-s$ curves of combined pile decreases, and CFGLP-RCSSP is closed to linear relation. The bearing capacity of the four composite pile of the CFGP, CFGLP-CFGSP, and CFGLP-RCSSP in the site are $225 \mathrm{kPa}, 179 \mathrm{kPa}$, and $197 \mathrm{kPa}$, separately increases 150\%, $98.8 \%$ and $119 \%$ compared to the Natural Foundation. 
Table 2. Model design parameter of composite foundation.

\begin{tabular}{cccccc}
\hline Model & Type & Pile length $/ \mathrm{m}$ & Pile diameter $/ \mathrm{mm}$ & Pile spacing $/ \mathrm{mm}$ & Replacement rate \\
\hline 1 & CFGP & 6.0 & 350 & 100 & 0.09616 \\
& & & 350 & 200 & 0.04808 \\
2 & CFGLP & 6.0 & 350 & 200 & 0.04808 \\
& CFGSP & 4.0 & 350 & 200 & 0.04808 \\
3 & CFGLP & 6.0 & 350 & 200 & 0.04808 \\
\hline
\end{tabular}

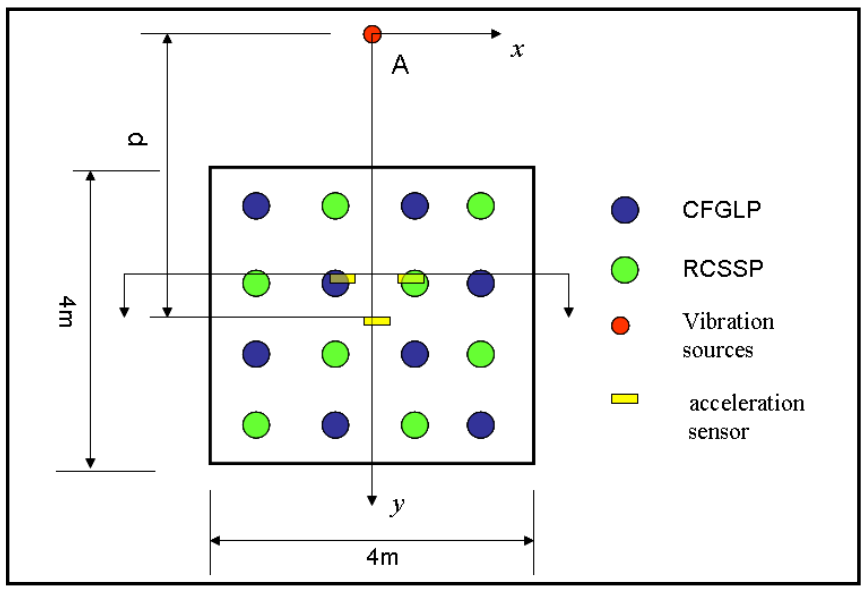

(a)

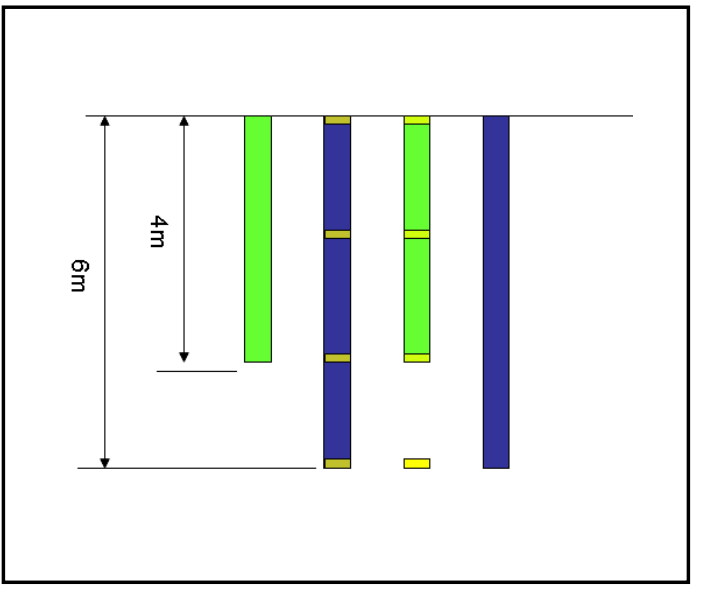

(b)

Figure 3. The arrangement of the piles and measuring elements of the Model 3. (a) Plane arrangement; (b) 1-1 profile arrangement.

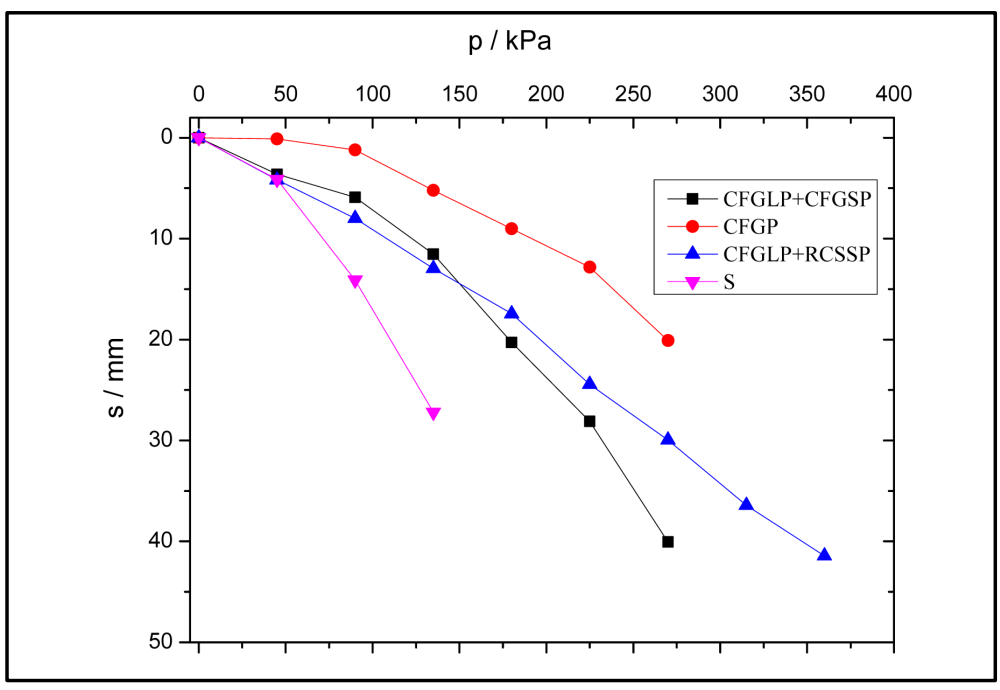

Figure 4. The $p$ - $s$ curves of the composite foundation.

\subsection{The Main Frequency of Vibration}

Field test shows that, under the same blast energy, vibration position, properties of foundation soil and form of composite foundation, have influence on the main frequency of composite foundation, but the rule is not obvious. Vibration main frequency depends on the properties of the soil and pile body between the vibration source and measuring point. When no load, the horizontal vibration main frequency of the natural foundation is at 8.2 $9.03 \mathrm{~Hz}$, and the vertical vibration main frequency is at $7.75-9.16 \mathrm{~Hz}$; the horizontal vibration main frequency 
CFGP composite foundation is at $21.1-27.7 \mathrm{~Hz}$, and the vertical vibration frequency is at 6.8 - $31.6 \mathrm{~Hz}$; the horizontal vibration main frequency of the CFGLP-CFGSP composite foundation is at $17.4-29.6 \mathrm{~Hz}$, and the vertical vibration main frequency is at $7.2-9.4 \mathrm{~Hz}$; the horizontal vibration main frequency of the CFGLP-RCSSP composite foundation is at 7.6 - $38.4 \mathrm{~Hz}$, and the vertical vibration main frequency is at $8.2-43.1 \mathrm{~Hz}$. Horizontal vibration main frequency greater than the vertical vibration main frequency, and the vertical main vibration frequency close to the natural frequency of composite foundation. With the load increasing, the main vibration frequency of the CFGLP-RCSSP composite foundation decreases. When the load is $180 \mathrm{kPa}$, the horizontal vibration main frequency of the CFGLP-RCSSP composite foundation is at $7.4-22.6 \mathrm{~Hz}$, and the vertical vibration main frequency is at $7.3-28.0 \mathrm{~Hz}$.

\subsection{Peak Acceleration Results}

Figures 5-7 are the peak acceleration with the horizontal distance $r$ from the measuring point to the vibration source without no pilling load on the CFGP composite foundation, when the depth of the vibration source is $6 \mathrm{~m}$ and the explosive quantity is $1.05 \mathrm{~kg}$. From Figure 4, in addition to individual point the horizontal peak acceleration is greater than the vertical peak acceleration, and with the increase of $r$, the difference gradually decreases. From Figures 5-7, outside the scope of the composite foundation, the peak acceleration significantly decreased with the increase of the pilling load; in the surface of compound foundation, pilling load action makes the peak acceleration gently.

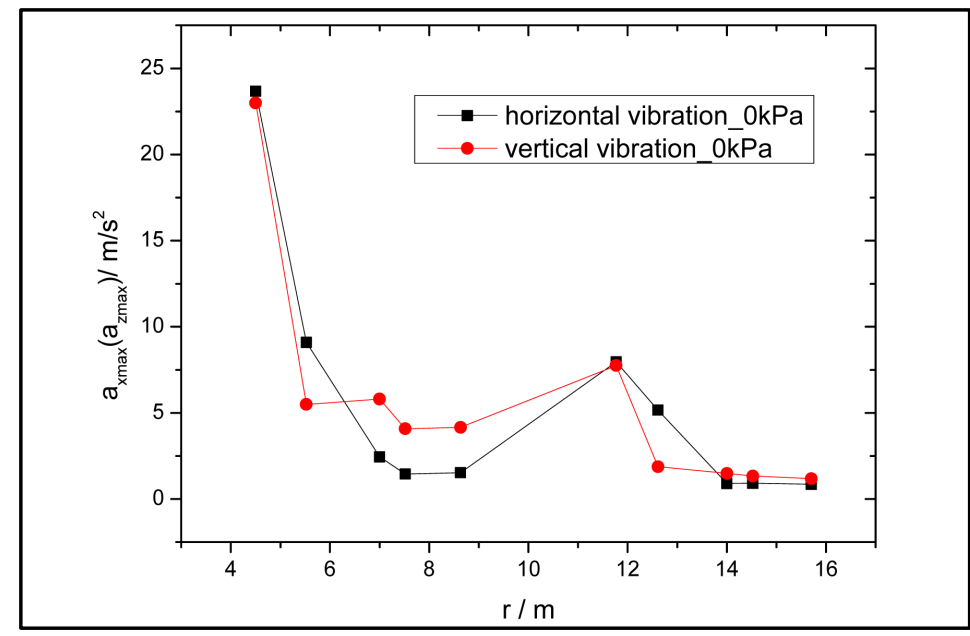

Figure 5. $a_{x \max }\left(a_{\mathrm{zmax}}\right)-r$ of CFGP composite foundation (no load).

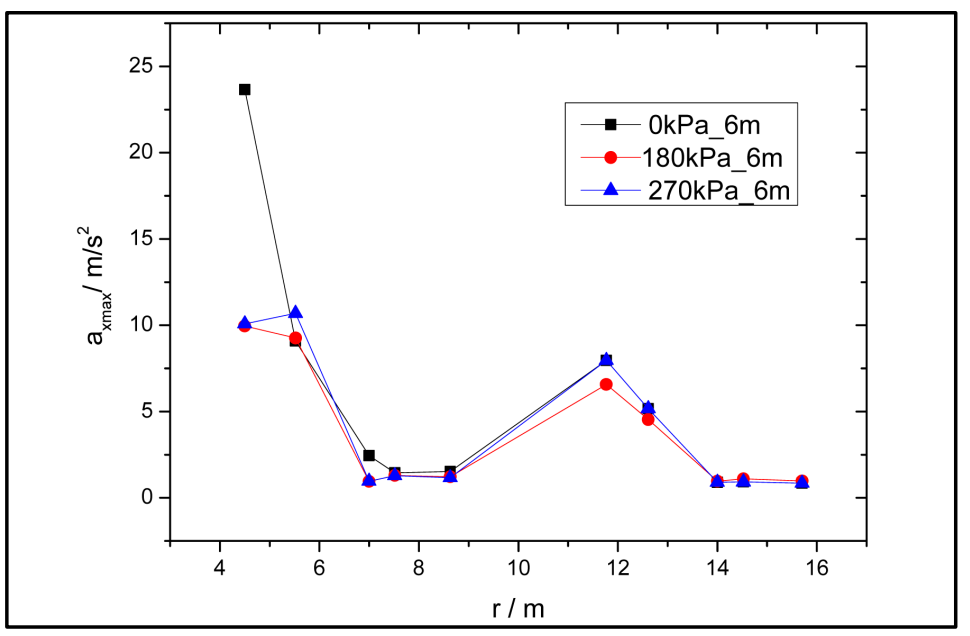

Figure 6. $a_{x \max }-r$ of CFGP composite foundation. 


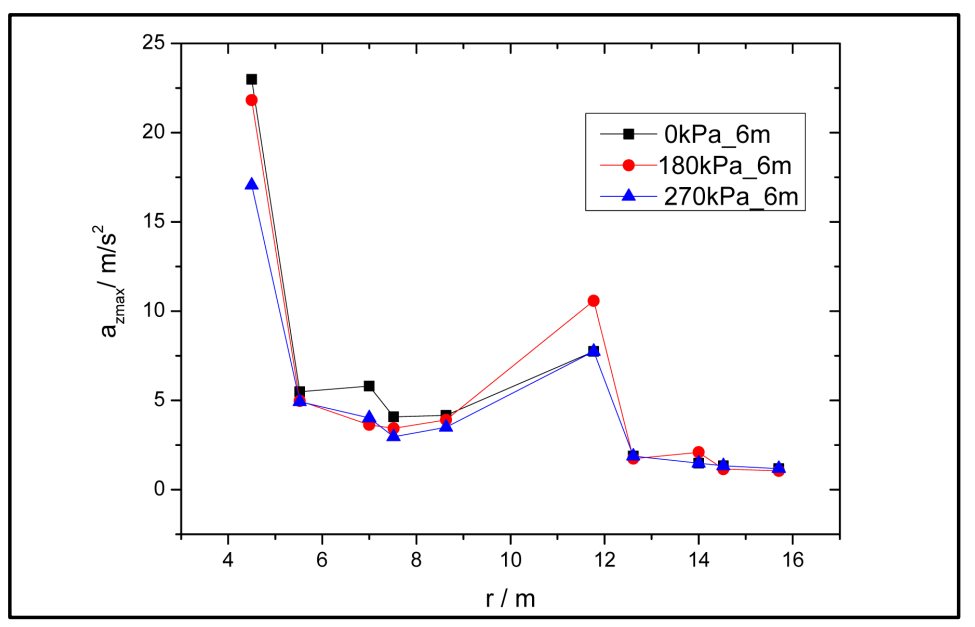

Figure 7. $a_{\text {zmax }}-r$ of CFGP composite foundation.

When the depth of the vibration source is $6 \mathrm{~m}$ and $r=7-8.6 \mathrm{~m}$, with the no-load, the horizontal acceleration peak of the CFG pile composite foundation surface is at $2.44-1.53$, and the vertical acceleration peak is 5.8 4.2; while pilling load is $270 \mathrm{kPa}$, the horizontal acceleration peak is $1.00-1.17$, and vertical acceleration peak is $4.01-3.96$.

When the distance from vibration source to the center of CFGP composite foundation distance is $14 \mathrm{~m}$ and the depth of vibration source is $6 \mathrm{~m}$ from the ground, the ratio of horizontal acceleration and vertical acceleration peak is at $0.61-2.75$, the measuring point outside CFGP composite foundation when the distance $r$ is $1 \mathrm{~m}$, the ratio was 1.03, and near to 1.0. When the distance from vibration source to the center of CFGP composite foundation distance is $7 \mathrm{~m}$ and the depth of vibration source is $6 \mathrm{~m}$ from the ground, the ratio of horizontal acceleration and vertical acceleration peak is at 0.36 - 1.65; the farther the horizontal distance $r$ from the measuring point to vibration source is, the greater the ratio.

Figures 8 and 9 are the peak acceleration with the horizontal distance $r$ from the measuring point to the vibration source without no pilling load on the CFGLP-CFGSP composite foundation, when the depth of the vibration source is $6 \mathrm{~m}$ and the explosive quantity is $1.05 \mathrm{~kg}$. From Figures 8-10, the peak acceleration along the CFGLP on the CFGLP-CFGSP composite foundation is near to peak acceleration of the CFGSP.

When the depth of the vibration source is $6 \mathrm{~m}$ and $r$ is at $7-8.6 \mathrm{~m}$, with the no-load, the horizontal peak acceleration of the CFGLP-CFGSP composite foundation surface is at $9.05-1.53 \mathrm{~m} / \mathrm{s}^{2}$, and the vertical peak acceleration is $13.27-2.72 \mathrm{~m} / \mathrm{s}^{2}$; while $\mathrm{r}$ is at $14-15.7 \mathrm{~m}$, the horizontal peak acceleration is $5.23-2.25 \mathrm{~m} / \mathrm{s}^{2}$, and vertical peak acceleration is $5.13-0.7 \mathrm{~m} / \mathrm{s}^{2}$.

When the distance from vibration source to the center of CFGLP-CFGSP composite foundation distance is 14 $\mathrm{m}$ and the depth of vibration source is $6 \mathrm{~m}$ from the ground, the ratio of horizontal acceleration and vertical acceleration peak is at $1.02-3.15$, measuring point distance from the vibration source is equal, the ratio is 1.49 on the CFGSP measuring point, and ratio is 3.15 on the CFGLP measuring point.

When the distance from vibration source to the center of CFGLP-CFGSP composite foundation distance is 7 $\mathrm{m}$ and the depth of vibration source is $6 \mathrm{~m}$ from the ground, the ratio of horizontal acceleration and vertical acceleration peak is at $0.69-1.91$, measuring point distance from the vibration source is equal, the ratio is 1.91 on the CFGSP measuring point, and ratio is 1.71 on the CFGLP measuring point. the farther the horizontal distance $r$ from the measuring point to vibration source is, the greater the ratio.

Figures 11-18 are CFGLP and RCSSP peak acceleration changes of the CFGLP-RCSSP composite foundation with vibration source depth and pilling load, when the explosive quantity is $1.05 \mathrm{~kg}$ and pilling load is 360 $\mathrm{kPa}$.

Figure 11 is the distribution law of the horizontal vibration peak acceleration on the CFGLP of the CFGLPRCSSP composite foundation. The depth of the vibration source is separately $2.5 \mathrm{~m}$ and $6 \mathrm{~m}$, the horizontal vibration peak acceleration distribution is almost consistent. When the depth location of the vibration source is 7 $\mathrm{m}$, the horizontal vibration peak acceleration maximum is at $\mathrm{z}=4 \mathrm{~m}$; when the location of the vibration source is $14 \mathrm{~m}$, the horizontal vibration peak acceleration maximum is at $z=0 \mathrm{~m}$. 


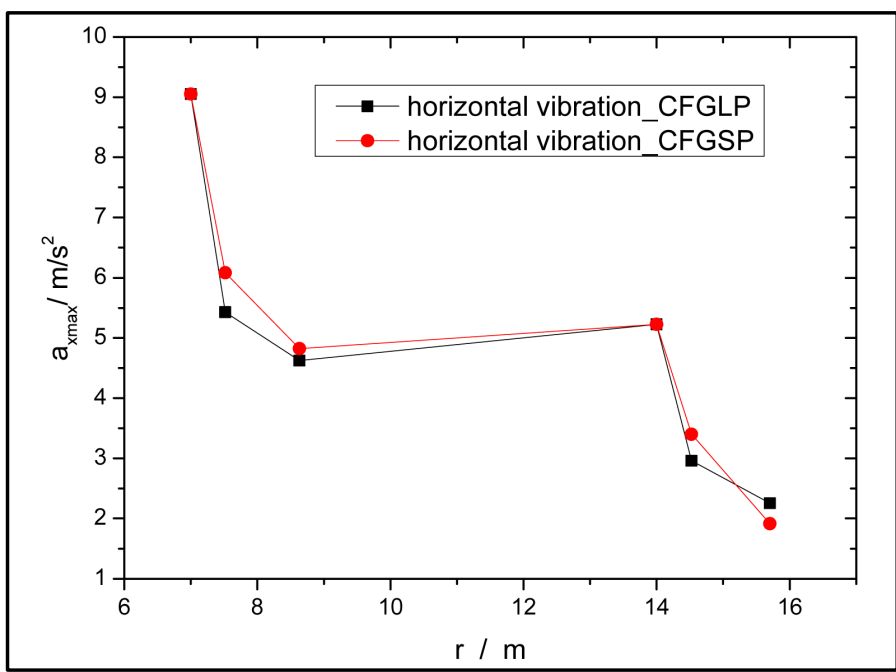

Figure 8. $a_{x \max }-r$ of CFGLP-CFGSP composite foundation.

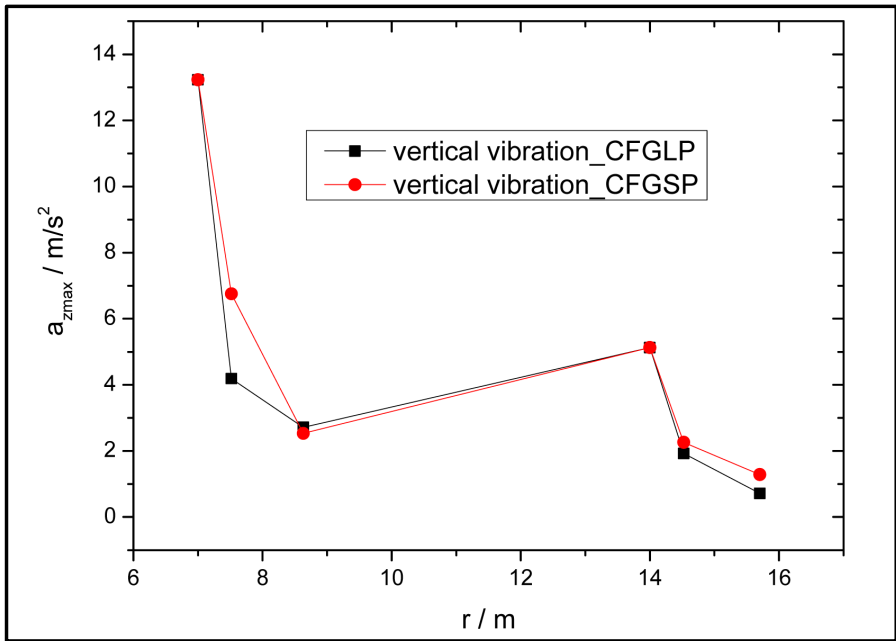

Figure 9. $a_{z \max }-r$ of CFGLP-CFGSP composite foundation.

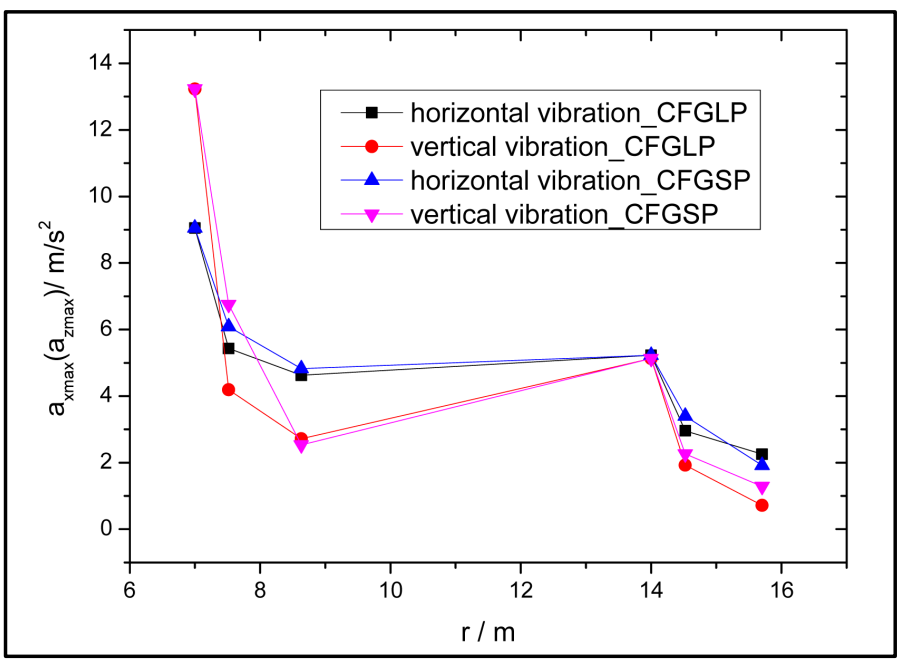

Figure 10. $a_{x \max }\left(a_{\mathrm{zmax}}\right)-r$ of CFGLP-CFGSP composite foundation. 


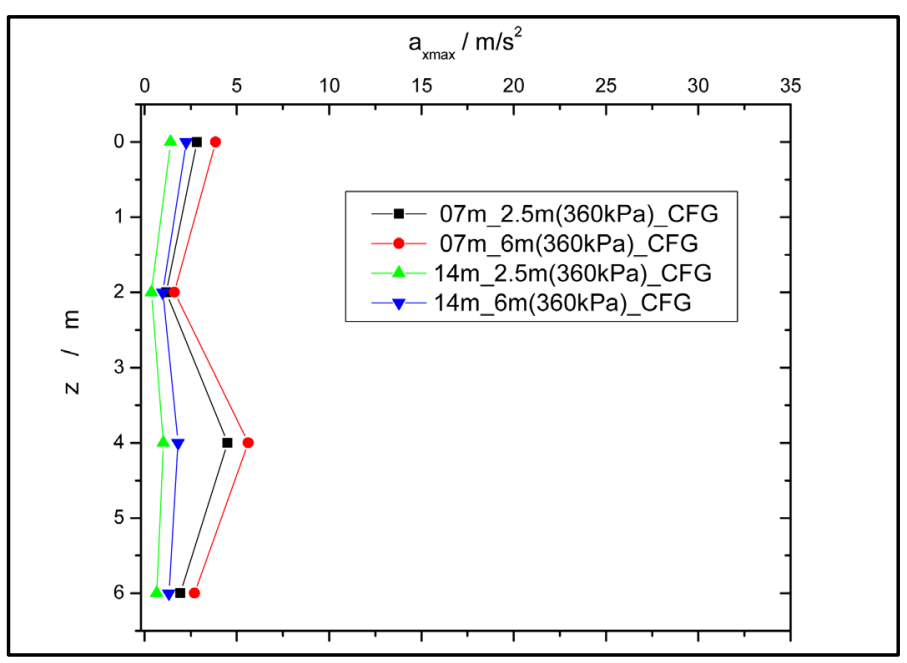

Figure 11. The peak acceleration $a_{x \max }$ along the CFGLP.

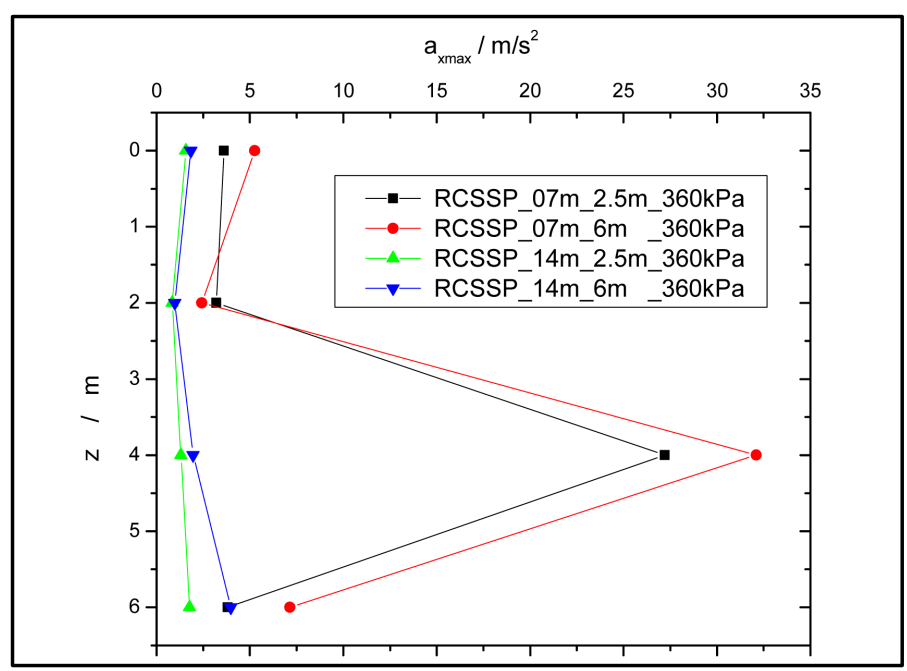

Figure 12. The peak acceleration $a_{x \max }$ along the RCSSP.

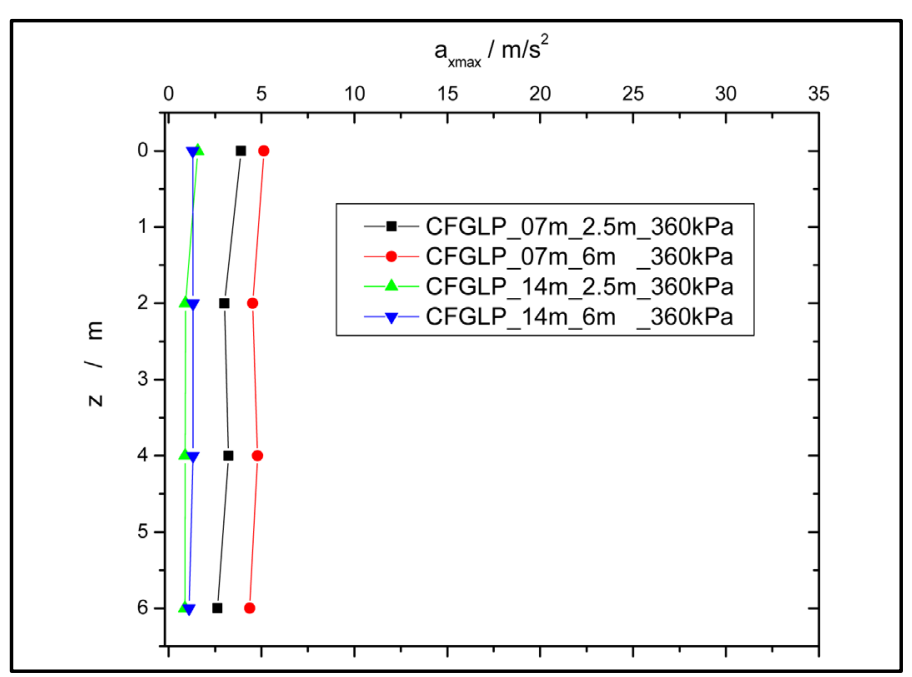

Figure 13. The peak acceleration $a_{\text {zmax }}$ along the CFGLP. 


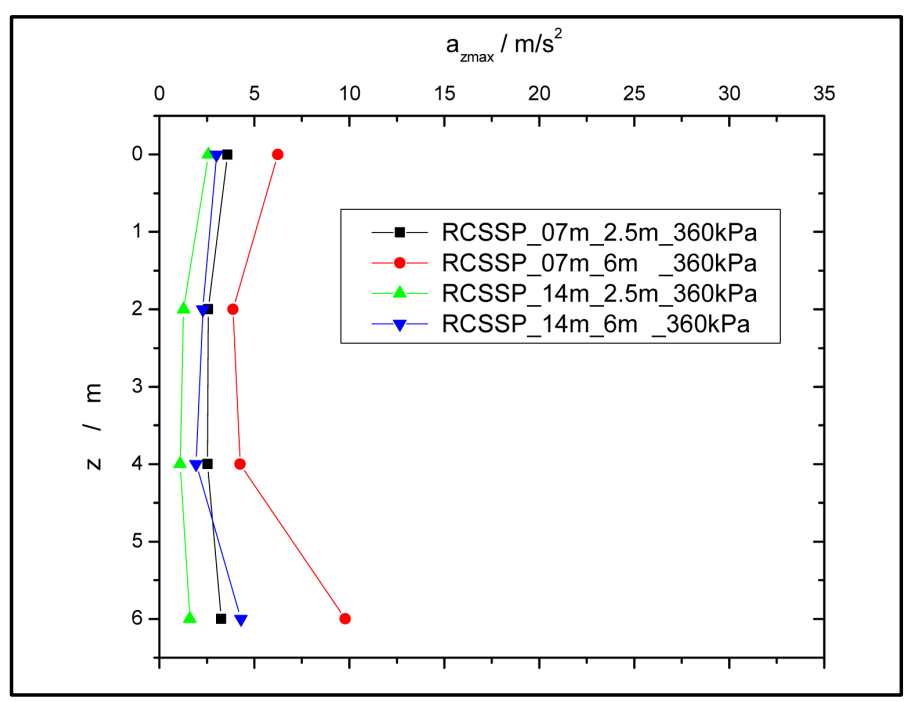

Figure 14. The peak acceleration $a_{\text {zmax }}$ along the RCSSP.

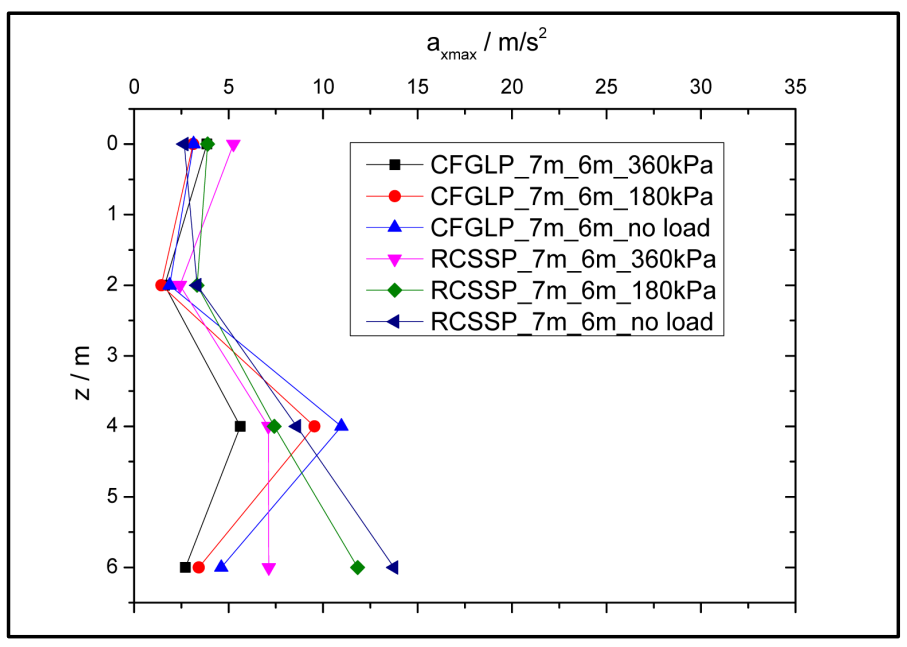

Figure 15. $a_{x \max } \mathrm{z}$ in CFGLP-RCSSP composite foundation.

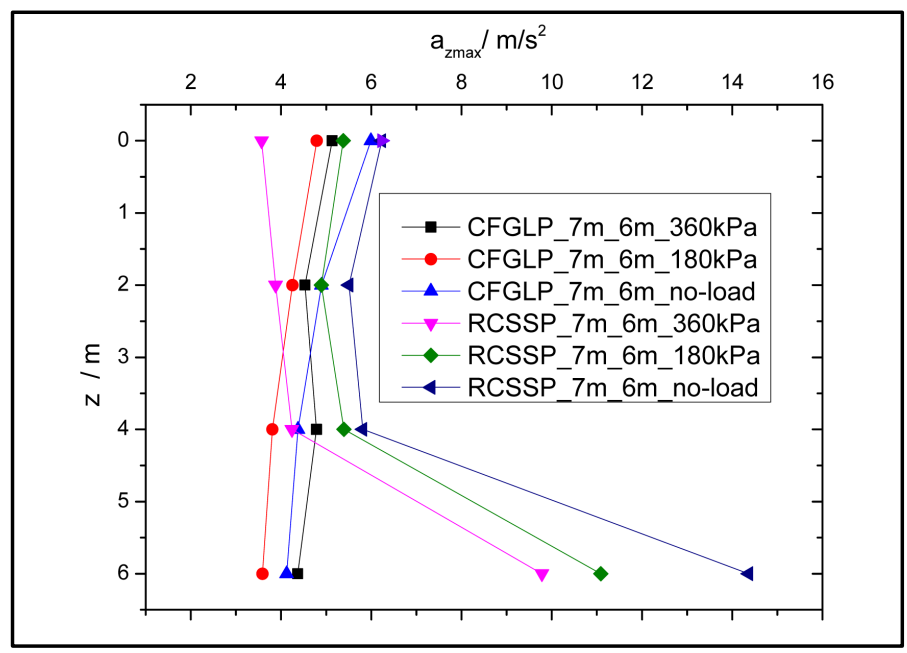

Figure 16. $a_{\text {zmax }} \mathrm{z}$ in CFGLP-RCSSP composite foundation. 


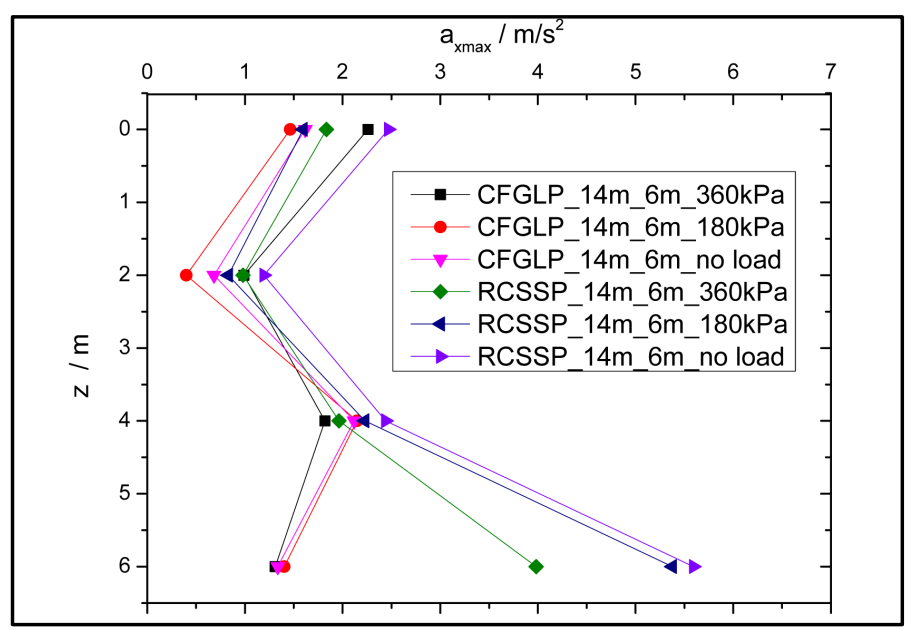

Figure 17. $a_{x \max }-\mathrm{Z}$ in CFGLP-RCSSP composite foundation.

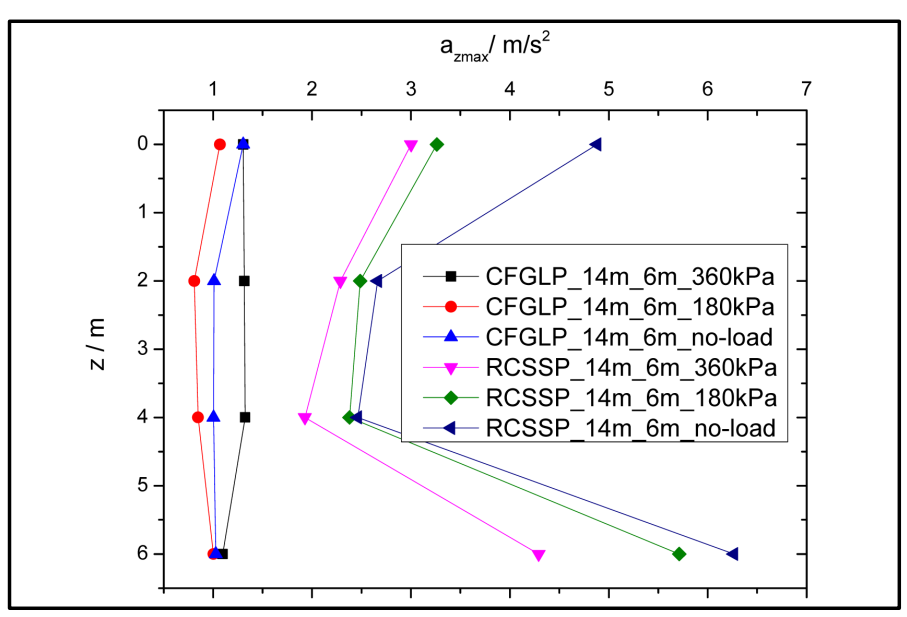

Figure 18. $a_{\mathrm{zmax}} \mathrm{z}$ in CFGLP-RCSSP composite foundation.

Figure 12 is the distribution law of the horizontal vibration peak acceleration on the RCSSP of the CFGLPRCSSP composite foundation. When the depth location of the vibration source is $7 \mathrm{~m}$, the horizontal vibration peak acceleration maximum is at $z=4 \mathrm{~m}$; when the location of the vibration source is $14 \mathrm{~m}$, the horizontal vibration peak acceleration maximum is at $z=6 \mathrm{~m}$.

Figure 13 is the distribution law of the Vertical vibration peak acceleration on the CFGLP of the CFGLPRCSSP composite foundation. The vertical vibration acceleration peak on the CFGLP is change little, and the vertical vibration peak acceleration maximum is at $z=0 \mathrm{~m}$.

Figure 14 is the distribution law of the Vertical vibration peak acceleration on the RCSSP of the CFGLPRCSSP composite foundation. The vertical vibration acceleration peak on the RCSSP is change little, and the vertical vibration peak acceleration maximum is at $z=0 \mathrm{~m}$.

Figures 14-18 are the distribution law of the vibration peak acceleration along the pile of the CFGLP-RCSSP composite foundation. With the increase of pilling load on CFGLP-RCSSP of the composite foundation the peak acceleration is reduced, the change range of composite foundation of $4 \mathrm{~m}$ pile body acceleration is consistent, the peak acceleration of the measuring point of the RCSSP is larger than that of the CFGLP. The maximum of the horizontal acceleration peak occurs in $z=4 \mathrm{~m}$ or $z=0 \mathrm{~m}$. The maximum of the vertical acceleration peak occurs in $z=0 \mathrm{~m}$.

\section{Conclusions}

The nonlinear degree of the $p$ - s curves of combined pile composite foundation decreases, and CFGLP-RCSSP 
is closed to linear relation. The bearing capacity of the four composite piles of the CFGP, CFGLP-CFGSP, and CFGLP-RCSSP in the site are separately $225 \mathrm{kPa}, 179 \mathrm{kPa}$, and $197 \mathrm{kPa}$, separately increases $150 \%$, 98.8\% and $119 \%$ compared to the natural Foundation.

The field test shows that, under the same blast energy, vibration source position, form of composite foundation and properties of foundation soil, influence the main frequency of the composite foundation, but the rule is not obvious. The vibration main frequency is mainly depended on properties of foundation soil and piles between vibration source and measuring point, pilling load value. Horizontal vibration main frequency greater than the vertical vibration main frequency and the vertical vibration main frequency close to the first-order natural frequency of composite foundation. With the pilling load increasing, the CFGLP-RCSSP pile composite foundation combined frequency decreased.

The field test shows that, under the same blast energy, vibration source position, the acceleration peak on the CFGP composite foundation is less than CFGLP-CFGSP the corresponding values, as the load increases, the peak acceleration gently. CFGP composite foundation is favorable on seismic.

Field test shows that, under the same blast energy, vibration source positions, form of composite foundation, properties of foundation soil and pilling load have a significant effect on the peak acceleration of composite foundation. The distribution of peak acceleration is consistent within $4 \mathrm{~m}$ from pile top in the CFGLP-RCSSP composite foundation. The maximum of the horizontal acceleration peak along the pile body occurs at a distance of pile top $4 \mathrm{~m}$ or the pile top, and that of vertical acceleration peak occurred at a pile top.

\section{Funding}

This work was supported by The Natural Science Foundation of Hebei Province under Grant (No. 2011E080601).

\section{References}

[1] (2002) GB50007-2002 Code for Design of Building Foundation(s). China Architecture Industry Press, Beijing.

[2] Yoshio, S. (1983) Deep Mixing Chemical Method Using Cement as Hardening Agent. Symposium on Soil and Rock Improvement Techniques, Bangkok, 34-37.

[3] Horii, N., Toyosawa, Y., Tamate, S. and Hashizume, H. (1998) Stability of Composite Ground Improved by Deep Mixing Method. Proceedings of 2nd International Conference on Ground Improvement Techniques, Singapore, 193198.

[4] Zheng, G. and Jiang, X.L. (1999) Research on the Bearing Capacity of Cement Treated Composite Foundation. Rock and Soil Mechanics, 3, 46-50.

[5] Ma, H.L. (2003) Quantitative Analyses of the Influence of Pile Length and Other Factors on Capability and Modul of Cement Stabilized Soil Composite Foundation. Chinese Journal of Geotechnical Engineering, 11, 720-723.

[6] Fu, J.H. and Song, E.X. (2000) Analysis of Rigid Pile Composite Foundation's Working Performance. Rock and Soil Mechanics, 21, 335-339.

[7] Wang, M.-S., Wang, G.-C., Yan, X.-F., et al. (2005) In-Situ Tests on Bearing Behavior of Multi-Type-Pile Composite Subgrade. Chinese Journal of Geotechnical Engineering, 27, 1142-1145.

[8] Yan, M.L., Wang, M.S., Yan, X.F. and Zhang, D.G. (2003) Study on the Calculation Method of Multi-Type-Pile Composite Foundation. Chinese Journal of Geotechnical Engineering, 25, 352-355.

[9] Ding, J.H. (2007) Reliability Analysis on the Bearing Capacity of Composite Foundation with Multi-Type Compound Piles. Engineering Mechanics, 25, 168-172.

[10] Ding, J.H., Liu, F.R. and Du, E.X. (2008) Dynamic Characteristic Analysis on Composite Foundation with Soil-Cement Piles and CFG Piles. Fly-Ash Comprehensive Utilization, 6, 37-40.

[11] Wang, W.Y., Zhao, T. and Meng, Y.J. (2012) The Numerical Analysis on Dynamic Characteristics of CFG Pile Composite Foundation under Blasting. Engineering Mechanics, 29, 150-155.

[12] Wang, W.Y., Zhao, T. and Ding, J.H. (2011) Effects on Dynamic Characteristics and Response of Rammed Soil-Cement Pile Composite Foundation. Engineering Mechanics, 28, 187-191.

[13] Wang, W.Y., Zhao, T. and Ding, J.H. (2010) Influence Factors of Dynamic Characteristics and Response of CFG Pile Composite Foundation. Chinese Journal of Geotechnical Engineering, S2, 115-118.

[14] Zhao, T., Yang, C.M. and Wang, W.Y. (2010) The Dynamic Test Research on CFG Pile Composite Foundation under 
J. H. Ding et al.

Blasting. Journal of Highway and Transportation Research and Development (Applied Technique), 7, 121-122.

[15] Ding, J.H., Wang, W.Y., Zhao, T., et al. (2013) The Dynamic Characteristic Experimental Method on the Composite Foundation with Rigid-Flexible Compound Piles. Open Journal of Civil Engineering, 3, 94-98.

http://dx.doi.org/10.4236/ojce.2013.32010 